\title{
Prolamin storage proteins and alloploidy in wild populations of the small grass Brachypodium distachyon (L.) P. Beauv.
}

\author{
Rifka Hammami • Nicolás Jouve • Angeles Cuadrado • \\ Consuelo Soler • Juan Manuel González
}

Received: 7 September 2010 / Accepted: 26 June 2011/Published online: 30 July 2011

(C) The Author(s) 2011. This article is published with open access at Springerlink.com

\begin{abstract}
This paper reports the glutenin diversity of a collection of 23 wild populations of the grass Brachypodium distachyon collected in the Mediterranean and southern areas of the Iberian Peninsula. The plant material studied included the three different cytotypes of this species: $2 n=10,2 n=20$ and $2 n=30$. A specific method of extraction was used to isolate the glutenin subunits from the caryopsis. Separation by sodium dodecyl sulphate polyacrylamide gel electrophoresis (SDS-PAGE) showed them to correspond to wheat low-molecular-weight glutenin subunits (LMW-GS). Twenty-two LMW-GS-like were identified that showed great diversity within and between populations. All the populations investigated were polymorphic for the endosperm proteins studied. The $2 n=30$ forms had the largest number of subunits; these were also more diverse than those of the $2 n=10$ or $2 n=20$ forms. The $2 n=10$ forms, the most common in the higher, interior areas of the Iberian Peninsula, showed the smallest subunit variation. In fact, negative correlations were found between subunit diversity and altitude and longitude. In contrast, a positive correlation was detected with the annual average temperature and the indices of thermicity and Mediterraneity. The similarity between the populations was estimated using the Sorensen-Dice coefficient, calculated on the basis of the presence/absence of the 22
\end{abstract}

R. Hammami · N. Jouve $(\bowtie)$ · A. Cuadrado · J. M. González Departmento de Biología Celular y Genética, Campus Universitario, University of Alcalá,

28871 Alcalá de Henares (Madrid), Spain

e-mail: nicolas.jouve@uah.es

C. Soler

Departmento de Medio Ambiente, INIA,

Finca La Canaleja, Alcalá de Henares (Madrid), Spain
LMW-GS proteins. The similarity indices were used to produce a dendrogram using the unweighted pair-group method with arithmetic means (UPGMA). This method produced three main groups corresponding to the three cytotypes. An analysis was made of the possible correlation between eco-geographic and climatic factors and the gene diversity and polymorphism shown in the populations. The diversity correlated positively with the number of chromosomes $(2 n)$, annual mean temperature, index of thermicity and index of Mediterraneity. In contrast, diversity correlated negatively with altitude, longitude and index of precipitation during the summer. The number of chromosomes correlated negatively with altitude, longitude and precipitation during summer and positively with all the other climatic indices. These results are coherent with the fact that diploid forms were more common in areas of the interior and at higher altitude, where the climate is more extreme.

Keywords Brachypodium distachyon - Glutenins · Endosperm proteins · Genetic diversity · Allopolyploidy

\section{Introduction}

Brachypodium distachyon (L.) P. Beauv., a self-pollinating species, is fast emerging as a powerful model for studying the grass family, including wheat and other temperate grasses. As a model it offers several attractive attributes such as a small ( $\sim 300 \mathrm{Mbp})$, recently sequenced genome (International Brachypodium Initiative, 2010) and a short lifecycle (Higgins et al. 2010). In addition it can be easily transformed.

Several investigations have shown Brachypodium to be closely related to wheat and other small grain cereals such 
as barley and oat (Catalan et al. 1997; Catalan and Olmstead 2000). The close phylogenetic relationship between Brachypodium and wheat is also reflected in the strong similarity of their gene sequences (Ozdemir et al. 2008). Indeed, there is a general coincidence in the order of Brachypodium genes and those of the other species of the tribe Triticeae, while the genome size is similar to that of rice. Brachypodium is therefore seen as a "bridge" between rice and the Triticeae tribe. Various molecular phylogenetic analyses have shown that Brachypodium diverged from the ancestral stock of Pooideae immediately prior to the radiation of the modern "core pooids" (Catalan et al. 1997; Catalan and Olmstead 2000; Draper et al. 2001). It is also ancestral, but equally related to, Avena and Triticum (Kellogg 2001; Huo et al. 2009).

The species of the genus Brachypodium have small chromosomes of variable number $(x=5,7,8,9$ or 10$)$, making them unusual among the members of the Pooideae, which tend to have large chromosomes and base number of 7 (Shi et al. 1993; Draper et al. 2001; Hasterok et al. 2004, 2006; Idziak and Hasterok 2008; Garvin et al. 2008). Although ecotypes of B. distachyon with 10, 20 and 30 chromosomes have been described, some authors have indicated that these numbers do not represent a simple autopolyploid series (Robertson 1981). The $2 n=10$ and $2 n=20$ ecotypes appear to be diploids, and it is generally assumed that the $2 n=30$ forms must be allotetraploids produced by the addition of the $2 n=10$ and $2 n=20$ genomes (Hasterok et al. 2004; Filiz et al. 2009). The $2 n=20$ and $2 n=30$ forms of Brachypodium are easily distinguished by visual examination from the $2 n=10$ form (Vogel et al. 2009).

$B$. distachyon has a rapid generation cycle under optimized conditions (8-12 weeks), does not grow very tall $(20-30 \mathrm{~cm})$ at high planting densities, requires few demanding growth resources, shows good environmental adaptation (Vogel et al. 2009) and the $2 n=10$ forms do not require vernalization (Draper et al. 2001; Ozdemir et al. 2008; Vogel et al. 2006). The species B. distachyon has been used to protect rural soils from erosion, especially in slope areas where water runoff, wind and other agents cause soil loss. Recently, some varieties of B. distachyon have been marketed in Spain to protect olive groves from erosion (Soler et al. 2004).

Despite the substantial body of knowledge now accumulated on Brachypodium, little is known about the biochemical composition and variability of its grain. Brachypodium seeds are typical of the Poaceae family with caryopses smaller than all other grass species (Opanowicz et al. 2008). The major grain components are seed storage proteins, which account for about $60-80 \%$ of total protein load, depending on species and variety. When classified according to their solubility, the grain storage proteins of cereals fall into three fractions: water-soluble albumins, dilute saline-soluble globulins and prolamins that are soluble in alcohol/water solutions under reducing conditions (Shewry and Tathan 1995). Laudencia-Chingcuanco and Vensel (2008) studied the grain filling process and seed storage proteins of $B$. distachyon grains and reported globulins to be the major protein components. Recently, Larré et al. (2010) showed that B. distachyon lacks albumins; globulins and prolamins are the main seed storage proteins. The globulins are represented mainly by the $11 \mathrm{~S}$ type, their solubility properties being very similar to the glutelin found in rice. However, the study of Larré was restricted to a single diploid inbred line isolated from the original accession Bd21 by Vogel and Hill (2008). More recently, Wang et al. (2010) studied the composition of the grain proteins of $13 \mathrm{~B}$. distachyon accessions (three with $2 n=10$, and ten with $2 n=30$ ) and reported the major storage proteins in these plants to be wheat low-molecularweight glutenin subunit-like (LMW-GS-like proteins) and globulins. A few high-molecular-weight glutenin subunits (HMW-GS) produced at low expression levels are also present. For a deeper knowledge of the storage proteins of $B$. distachyon to be gained, however, more materials need to be studied, analyzing the degree of diversity of the storage proteins within and between different wild populations, and examining the relationship of this diversity with the number of chromosomes and the ecological, geographical and climatic conditions of the places where samples are collected.

The increasing interest in the genetic resources of Brachypodium has led to several germplasm collections coming into existence (Doust 2007; Huo et al. 2008; Vain et al. 2008; Vogel and Hill 2008; Garvin 2007). Knowledge of the genetic diversity in wild populations of $B$. distachyon is central to the development of its effective conservation in genebanks and the use of this primitive grass in breeding strategies. One of the present authors (C.S.) undertook several expeditions to different regions of the Iberian Peninsula and produced a good collection of natural populations of $B$. distachyon. A group of these populations, selected by their differences in terms of ecogeographic origin and number of chromosomes, formed the material examined in the present work.

The aim of this study is to characterize the genetic variability of the endosperm LMW-GS-like proteins in a collection of wild populations of B. distachyon gathered in Spain, using two marketed varieties as controls. The samples examined belong to all three cytotypes $(2 n=10$, $2 n=20,2 n=30$ ). The above proteins were characterized and an analysis made of their natural diversity in relation to chromosome number and eco-geographic variables. 


\section{Materials and methods}

Plant material

Spain is remarkably rich in wild populations of this species. In recent years (2000-2008) a number of expeditions were undertaken to collect samples from wild populations in the southern and Mediterranean areas of the Iberian Peninsula. To preserve the original structure of the natural populations, specimens were collected at random following the method of Hawkes (1980). A total of 23 wild populations of $B$. distachyon from these different geographic regions were used as plant material in this work. Two commercial varieties, 'Ibros' $(=\mathrm{Bd} 3107 ; 2 n=30)$ and 'Zulema' (=Bd3113; $2 n=10)$, were used as controls. These were obtained via domestication of natural populations, selecting uniform lines over several generations to produce a turf for protection of degraded soils (Soler et al. 2004). Figure 1 shows the geographical location of each accession used in the present work, while Table 1 records their chromosome number and main eco-geographic features. The accessions studied form part of a collection held at the Unit of Plant Improvement of the Department of Ecology of the Instituto Nacional de Investigaciones Agrarias (INIA) at the La Canaleja Research Station (Alcalá de Henares, Madrid, Spain). Climatic data were collected at each collection site from the closest meteorological station. These included the annual average temperature, the Rivas-Martinez thermicity index (Rivas-Martínez et al. 1990), i.e. It $=(T+m+M)$ / 10 , annual precipitation in $\mathrm{mm}(P)$ and the index of Mediterraneity $(\mathrm{IM} 3=\mathrm{PET}$ June + July + August $/ P$ June + July + August $>2.5$, where PET is the monthly potential evapotranspiration of Thornthwaite (1948).

In December 2007, seeds from each accession of B. distachyon and both commercial lines were planted in individual 15 -cm-diameter plastic pots. Plants were grown under greenhouse conditions until March. All plants were then transferred outside the greenhouse until ripening. At maturity, ears from each plant were bagged to avoid mixture of seeds, and all ears were harvested. Flour was then made from 10 seeds per plant for 12 plants from each of the above materials. Caryopses were independently ground in a mortar. The seeds of Brachypodium are very hard, so liquid nitrogen was used to facilitate this process. The flour produced was left for $24 \mathrm{~h}$ in an oven at $37^{\circ} \mathrm{C}$ before extracting the proteins.

\section{SDS-PAGE analysis}

To identify the major seed storage proteins, differential extraction of the total proteins was undertaken followed by denaturing one-dimensional (1D) SDS-PAGE. The differential extraction method used was a modification of that described by Singh et al. (1991). This modification allowed the gliadins and glutenins to be separated; this work, however, only reports the analysis of the glutenins.

Two hundred microlitres of solution A (propanol-1 50\% $\mathrm{v} / \mathrm{v}$ ) was added to $20 \mathrm{mg}$ flour extracted from the 10 seeds taken from single plants. These samples were shaken and incubated for $1 \mathrm{~h}$ in a water bath at $65^{\circ} \mathrm{C}$ before centrifuging at $10,000 \times g$ for $15 \mathrm{~min}$. The supernatant was eliminated, and $200 \mu \mathrm{l}$ solution A was added to the precipitate. The resulting samples were incubated for $30 \mathrm{~min}$ in a water bath at $65^{\circ} \mathrm{C}$, centrifuged at $12,000 \times g$ for $5 \mathrm{~min}$ and again the supernatant eliminated. Twenty microlitres of solution B (propanol-1 50\% v/v, mixed with $1 \mathrm{M}$ Tris$\mathrm{HCl} ; \mathrm{pH} 8$ ) and $1 \% \mathrm{v} / \mathrm{v}$ dithiothreitol (DTT) were added to the pellet to purify the glutenins. The resulting samples were then shaken and incubated for $30 \mathrm{~min}$ in a water bath at $65^{\circ} \mathrm{C}$. Solution B $(20 \mu \mathrm{l})$ and 4-vinylpiridine to $1.4 \% \mathrm{v} / \mathrm{v}$ were then added and the samples shaken and incubated for $15 \mathrm{~min}$ in a water bath at $65^{\circ} \mathrm{C}$. Finally, the samples were centrifuged at $10,000 \times g$ for $2 \mathrm{~min}$, and the supernatant, corresponding to the glutenin fraction, was recovered. Twenty microlitres of the supernatant was then mixed with $20 \mu$ solution $\mathrm{C}(0.2 \mathrm{~g} \mathrm{SDS}, 4 \mathrm{ml}$ glycerol, $2 \mathrm{mg}$ bromophenol blue, $0.8 \mathrm{ml}$ Tris- $\mathrm{HCl} 1 \mathrm{M} ; \mathrm{pH}=8$ ) to produce samples for electrophoretic analysis.

The protein samples of the 12 individual plants from each of the studied materials were separated on SDS-PAGE gels. Multimark proteins (Invitrogen) were used as molecular weight markers. Triticum aestivum cv. 'Chinese Spring' was used to provide a reference glutenin pattern. The SDS-PAGE method followed required the preparation of polyacrylamide gels with two different concentration areas: $3 \%$ acrylamide in the stacking area, and $12 \%$ in the separation zone. A constant voltage of $20 \mathrm{mV}$ was applied to the stacking area. This was increased to $40 \mathrm{mV}$ when the visualization medium approached the start of the separation zone. The gel was stained with a mixture of Coomassie blue G, Coomassie blue R, acetic acid, ethanol and trichloroacetic acid. The gels were washed with distilled water to eliminate excess dye, photographed and the images digitized.

Study of gels and data analysis

The total glutenins of the studied materials were examined independently. Following electrophoretic separation, the glutenin-like proteins were analyzed. Only LMW-GS bands were analyzed in the present study, using T. aestivum cv. 'Chinese Spring' as control. Variability was investigated by analysis of the presence/absence of each band in the electrophoretic profiles. A total of 22 bands were identified; these were numbered from 1 to $18 \mathrm{~A}$ from top to bottom in the gels (bands 9, 17 and 18, which 
Fig. 1 Geographic distribution of 23 collection sites throughout Spain

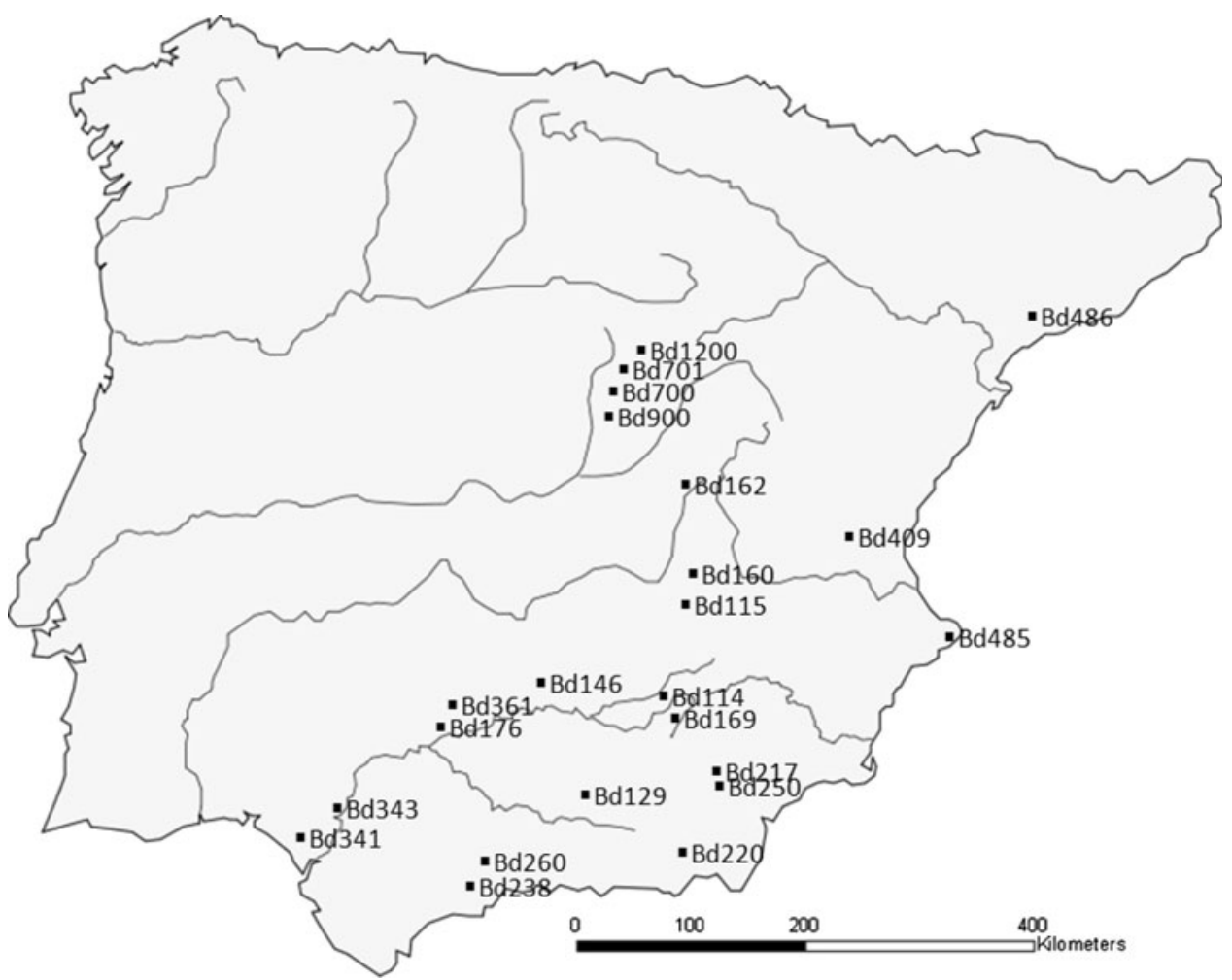

initially were considered as single bands, were later subdivided into two: 9 and 9A, 17 and 17A, 18 and 18A, due to perceivable differences of migration; 17 and 17A, 18 and 18A never coincided in the same plant). The presence/absence of each glutenin, the frequency of each in the set of plants analyzed per population, the different electrophoretic profiles and the pattern for each accession were recorded. A data matrix using " 1 " for presence and "0" for absence of each glutenin was constructed. A second matrix for the frequency of each band was also produced.

Factorial analysis of correspondences was used to examine the inter-population distances and the influence of each variable (proteins, eco-geographic factors and chromosome number) on the grouping of populations.

The similarity between the populations was reflected using the Sorensen-Dice coefficient (Sorensen 1948) calculated from the binary data (presence/absence) matrix for the 22 proteins. These similarity indices were used to produce a dendrogram using the unweighted pair-group method with arithmetic means (UPGMA) (Sneath and Sokal 1973). The NTSYS package was used for all analyses (Rolf 1994).

Analysis of within- and among-populations LMW-GS diversities were conducted using Nei's index of heterogeneity. The average diversity for all the LMW-GS studied was estimated considering the frequencies of each band in all loci in the 23 natural populations analyzed.
Chromosome preparations

Seeds of plants from each wild population and the commercial lines of $B$. distachyon were germinated on moist filter paper for $24 \mathrm{~h}$ at $25^{\circ} \mathrm{C}$. They were then left at $4^{\circ} \mathrm{C}$ for $72 \mathrm{~h}$ and returned to a temperature of $25^{\circ} \mathrm{C}$ for $24 \mathrm{~h}$ in order to synchronize cell divisions in the root tips. The roots were excised and pre-treated in cold water for $24 \mathrm{~h}$ before fixation in ethanol/acetic acid (3:1). Before squashing, the pretreated roots were fixed in a solution of 3:1 ethanol/acetic acid, washed and transferred to an enzyme solution containing $2 \%$ cellulose and $20 \%$ pectinase. Chromosome preparations were made by squashing the meristem of the root in a drop of $45 \%$ acetic acid on a clean microscope slide. After removal of the coverslips by freezing, the slides were air-dried, stained with the DNAbinding fluorochrome 4',6-diamidino-2-phenylindole (DAPI), and examined using a Zeiss Axiophot epifluorescence microscope.

FISH, GISH, probes and labelling

The DNA probes used in these analyses were pTa71, a 9-kb fragment from $T$. aestivum containing the $18 \mathrm{~S}$ ribosomal DNA (rDNA) sequence including the intergenic spacers (Gerlach and Bedbrook 1979), and pTa794 (a 410-bp fragment also from wheat containing the 5S rDNAgene repeat unit) (Gerlach and Dyer 1980). Genomic 
Table 1 Original identities, geographic data, source of the ecotypes, number of

chromosomes and climatic variables of the habitats of the 23 wild populations and two marketed varieties of

B. distachyon studied. Controls: Bd3017 (='Zulema') and Bd3113 (='Ibros').

Alt $=$ altitude in metres above sea level

\begin{tabular}{|c|c|c|c|c|}
\hline Material & $\begin{array}{l}\text { Geographical location: } \\
\text { latitude/longitude }\end{array}$ & Locality (province) & $2 n$ & Alt. (m) \\
\hline $\mathrm{Bd} 160$ & $38^{\circ} 57^{\prime} 00^{\prime \prime} / 2^{\circ} 31^{\prime} 59^{\prime \prime}$ & Bonillo (Albacete) & 10 & 1,035 \\
\hline Bd162 & $35^{\circ} 56^{\prime} 00^{\prime \prime} / 2^{\circ} 53^{\prime} 00^{\prime \prime}$ & Segóbriga (Cuenca) & 10 & 830 \\
\hline Bd169 & $37^{\circ} 43^{\prime} 00^{\prime \prime} / 2^{\circ} 59^{\prime} 00^{\prime \prime}$ & Sierra de Cazorla (Jaén) & 10 & 905 \\
\hline $\mathrm{Bd} 700$ & $40^{\circ} 55^{\prime} 34^{\prime \prime} / 2^{\circ} 55^{\prime} 29^{\prime \prime}$ & Jadraque (Guadalajara) & 10 & 701 \\
\hline Bd701 & $40^{\circ} 37^{\prime} 47^{\prime \prime} / 3^{\circ} 09^{\prime} 59^{\prime \prime}$ & Guadalajara (Guadalajara) & 10 & 900 \\
\hline $\mathrm{Bd} 900$ & $40^{\circ} 36^{\prime} 36^{\prime \prime} / 3^{\circ} 03^{\prime} 16^{\prime \prime}$ & Lupiana (Guadalajara) & 10 & 700 \\
\hline Bd1200 & $41^{\circ} 04^{\prime} 10^{\prime \prime} / 2^{\circ} 38^{\prime} 32^{\prime \prime}$ & Sigüenza (Guadalajara) & 10 & 1,200 \\
\hline $\mathrm{Bd} 3113$ & $35^{\circ} 56^{\prime} 00^{\prime \prime} / 2^{\circ} 53^{\prime} 00^{\prime \prime}$ & Segóbriga (Cuenca) & 10 & 830 \\
\hline Bd114 & $37^{\circ} 59^{\prime} 00^{\prime \prime} / 3^{\circ} 28^{\prime} 00^{\prime \prime}$ & Baeza (Jaén) & 20 & 661 \\
\hline Bd115 & $38^{\circ} 40^{\prime} 00^{\prime \prime} / 2^{\circ} 29^{\prime} 00^{\prime \prime}$ & Alcaráz (Albacete) & 20 & 949 \\
\hline Bd129 & $37^{\circ} 20^{\prime} 00^{\prime \prime} / 3^{\circ} 47^{\prime} 00^{\prime \prime}$ & Moclín (Granada) & 20 & 1,084 \\
\hline $\mathrm{Bd} 485$ & $38^{\circ} 44^{\prime} 18^{\prime \prime} / 0^{\circ} 13^{\prime} 56^{\prime \prime}$ & Cabo de la Nao (Alicante) & 20 & 42 \\
\hline Bd146 & $38^{\circ} 08^{\prime} 00^{\prime \prime} / 4^{\circ} 54^{\prime} 00^{\prime \prime}$ & Villaharta (Córdoba) & 30 & 759 \\
\hline Bd176 & $37^{\circ} 35^{\prime} 00^{\prime \prime} / 4^{\circ} 35^{\prime} 00^{\prime \prime}$ & Córdoba (Córdoba) & 30 & 445 \\
\hline $\mathrm{Bd} 217$ & $37^{\circ} 27^{\prime} 28^{\prime \prime} / 2^{\circ} 14^{\prime} 57^{\prime \prime}$ & Oria (Almería) & 30 & 829 \\
\hline $\mathrm{Bd} 220$ & $36^{\circ} 51^{\prime} 34^{\prime \prime} / 2^{\circ} 37^{\prime} 46^{\prime \prime}$ & Enix (Almería) & 30 & 540 \\
\hline $\mathrm{Bd} 238$ & $36^{\circ} 48^{\prime} 25^{\prime \prime} / 4^{\circ} 54^{\prime} 11^{\prime \prime}$ & Casarabonela (Málaga) & 30 & 575 \\
\hline $\mathrm{Bd} 250$ & $37^{\circ} 26^{\prime} 55^{\prime \prime} / 2^{\circ} 09^{\prime} 13^{\prime \prime}$ & Albox (Almería) & 30 & 636 \\
\hline $\mathrm{Bd} 260$ & $36^{\circ} 58^{\prime} 26^{\prime \prime} / 4^{\circ} 40^{\prime} 35^{\prime \prime}$ & Abdalajis (Málaga) & 30 & 528 \\
\hline $\mathrm{Bd} 341$ & $38^{\circ} 00^{\prime} 49^{\prime \prime} / 6^{\circ} 31^{\prime} 06^{\prime \prime}$ & Cañaveral de León (Huelva) & 30 & 546 \\
\hline $\mathrm{Bd} 343$ & $37^{\circ} 52^{\prime} 50^{\prime \prime} / 6^{\circ} 08^{\prime} 54^{\prime \prime}$ & Arroyo de la Cala (Sevilla) & 30 & 365 \\
\hline $\mathrm{Bd} 361$ & $38^{\circ} 12^{\prime} 37^{\prime \prime} / 4^{\circ} 01^{\prime} 48^{\prime \prime}$ & Nuestra Sra. de la Cabeza (Córdoba) & 30 & 651 \\
\hline $\mathrm{Bd} 409$ & $39^{\circ} 14^{\prime} 56^{\prime \prime} / 1^{\circ} 03^{\prime} 59^{\prime \prime}$ & Cofrentes (Valencia) & 30 & 452 \\
\hline $\mathrm{Bd} 486$ & $41^{\circ} 10^{\prime} 40^{\prime \prime} /-1^{\circ} 28^{\prime} 28^{\prime \prime}$ & Roda de Bará (Tarragona) & 30 & 23 \\
\hline $\mathrm{Bd} 3107$ & $37^{\circ} 35^{\prime} 00^{\prime \prime} / 4^{\circ} 35^{\prime} 00^{\prime \prime}$ & Córdoba (Córdoba) & 30 & 445 \\
\hline
\end{tabular}

in situ hybridization (GISH) was used to characterize the type of DNA present in the $2 n=30$ forms. For this, DNA from both $2 n=10$ and $2 n=20$ plants were used as probes. DNA was isolated from $B$. distachyon $\operatorname{Bd} 3113(2 n=10)$ and $\operatorname{Bd} 129(2 n=20)$ using the DNeasy Plant extraction kit (Qiagen). Probes were labelled with digoxigenin or biotin by nick translation (pTa71 and genomic DNA) and polymerase chain reaction (PCR) (pTa794). The digoxigenin and biotin were detected using anti-digoxigenin fluorescein isothiocyanate (FITC) conjugate (green) and streptavidin-Cy3 (red), respectively.

Preparations and probe denaturation, in situ hybridization, post-hybridization washing, and detection were all performed according to Cuadrado et al. (2004).

Fluorescence microscopy and imaging

Slides were examined using a Zeiss Axiophot epifluorescence microscope. The separate images from each filter set were captured using a cooled charge-coupled device
(CCD) camera (Nikon DS). Images were optimized for contrast and brightness using Adobe Photoshop.

\section{Results}

The chromosome number of the plants belonging to each population was initially analyzed by DAPI staining. This allowed the populations to be classified into the three known cytotypes which have 10,20 or 30 chromosomes (Table 1 ). The $2 n=10$ cytotype had three pairs of distinguishable chromosomes and another two smaller, indistinguishable pairs. The chromosomes of the $2 n=20$ cytotype were of similar size and indistinguishable, but smaller than those of the $2 n=10$ forms. Finally, the $2 n=30$ cytotype seemed to have two groups of chromosomes similar to those of the $2 n=10$ plus $2 n=20$ cytotypes.

Of the 23 populations analyzed, 8 were of the $2 n=10$ cytotype (Bd160, Bd162, Bd169, Bd700, Bd701, Bd900, $\mathrm{Bd} 1200$ and $\mathrm{Bd} 3113), 4$ were of the $2 n=20$ cytotype 


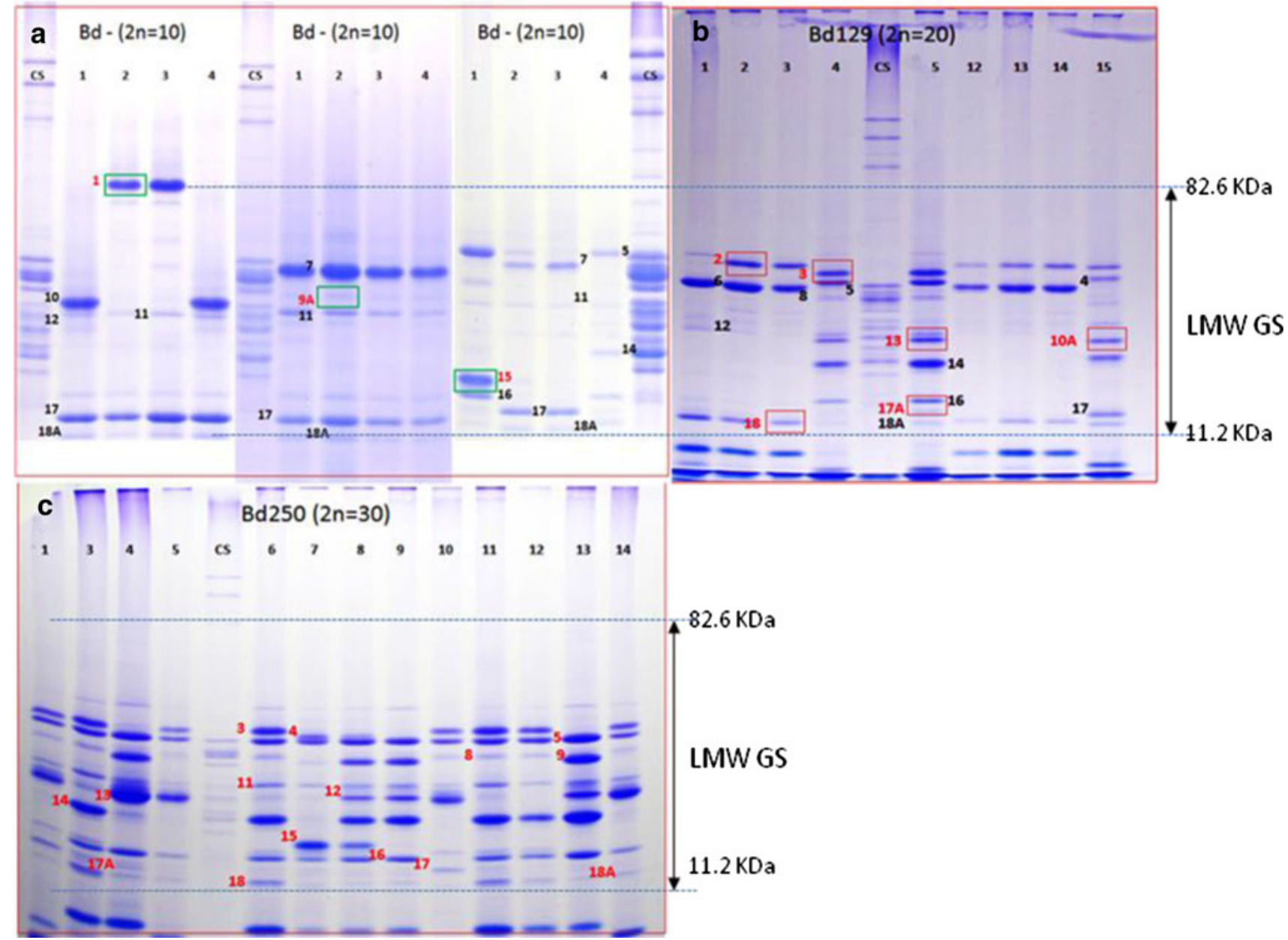

Fig. 2 The glutenins of B. distachyon. a Patterns of LMW-GS in different plants of three wild populations with $2 n=10$. Marks in green indicate bands that are present in forms with $2 n=10$ and $2 n=30$, but absent in $2 n=20$; $\mathbf{b}$ variation of storage proteins from total caryopses of different plants of Bd129 $(2 n=20)$. Marks in red indicate bands that are present in forms with $2 n=20$ and $2 n=30$, but absent in $2 n=10$. c Variation of storage proteins from total caryopses of 14 plants of $\operatorname{Bd} 250 \quad(2 n=30)$. CS glutenins of T. aestivum cv. 'Chinese Spring', $M$ molecular weight markers

aestivum cv. 'Chinese Spring' but lack clear protein bands in the HMW-GS region. The number of total proteins by population varied from $4(\mathrm{Bd} 160, \mathrm{Bd} 162, \mathrm{Bd} 1200$ with $2 n=10)$ to $16(\mathrm{Bd} 409,2 n=30)$ or $17(\mathrm{Bd} 220,2 n=30)$. Some proteins, such as LMW-GS 1, 9A, 10 or 10A, were present in very few populations. Others, such as LMW-GS 11 or 12, were absent in some populations. In general, each population showed a predominant pattern of glutenin subunits and each population was characterized by a mixture of a small number of different patterns. LMW-GS 11, 12, 17 and 18A were the most common among the material examined, and LMW-GS $1,2,6,9,9 \mathrm{~A}, 13,14$ and 15 the least common. LMW-GS 10 was only present in the diploid accession Bd169. LMW-GS 17 and $17 \mathrm{~A}$ and 18 and 18A showed a pattern of presence/ absence mutually excluding.

The 22 distinguishing proteins constitute a set of markers that could be used in the analysis of the diversity 
within and between populations. Table 2 summarizes the LMW glutenin diversities conducted by Nei's index, taking into account the set of bands detected in the 12 plants analyzed in each population. The populations have been ordered according their cytotypes. The final rows of each group present the average Nei index for the set of protein subunits in the different cytotypic groups. The last column records the mean heterogeneity index for each population, which varied from 0.01 to 0.44 . Interestingly, the $2 n=10$ forms showed the lowest Nei indices (from 0.01 in Bd701 and Bd900 to 0.09 in Bd160 and Bd169, with average of 0.05), whereas those with largest number of chromosomes were the most heterogeneous having higher Nei indices (average of 0.12 and 0.17 for the cytotypic groups of $2 n=20$ and $2 n=30$, respectively.

Of the 22 total LMW-GS found in the 23 natural populations analyzed, only subunit 10 was specifically found at the $2 n=10$ level (Bd169). A maximum of 21 bands was recorded for the $2 n=30$ forms. Of the LMW-GS, 1, 9A and 15 were present in the $2 n=10$ forms and absent in the $2 n=20$ forms, $2,3,10 \mathrm{~A}, 13,17 \mathrm{~A}$ and 18 were present in the $2 n=20$ forms but absent in the $2 n=10$ forms, and 4, 5, 6, 7, 8, 9, 11 , $12,14,16,17$ and $18 \mathrm{~A}$ were common to all forms. The confluence in the $2 n=30$ forms of different proteins found in the $2 n=10$ and $2 n=20$ forms sustains the hypothesis of the origin of the $2 n=30$ forms in the addition of the chromosomal complements of the $2 n=10$ and $2 n=20$ forms.

Figure 3 shows an example of the results obtained with population $\operatorname{Bd} 146(2 n=30)$ after FISH with the rDNA probes pTa71 and pTa794, followed by reprobing the same chromosome preparations with genomic DNA from $\operatorname{Bd} 3113(2 n=10)$ and $\operatorname{Bd} 129(2 n=20)$. FISH with pTa71 and pTa794 showed four signals each on eight different chromosomes. The pTa71 signals, two stronger and two weaker, were located at the distal region of two pairs of small chromosomes. The stronger 5S rDNA locus was found in a proximal region of a medium metacentric chromosome, while the fainter one was visualized in the distal region of a small pair of chromosomes (Fig. 3a). After reprobing with $2 n=10$ cytotype genomic DNA, two groups of chromosomes became distinguishable via their fluorescence patterns. Twenty small chromosomes showed fluorescence signals exclusively around the centromeres, and 10 chromosomes of different sizes showed a dispersed pattern of signals along the length of their arms (Fig. 3b). Reprobing metaphase chromosomes of $2 n=30$ plants with $2 n=20$ cytotype genomic DNA revealed signals exclusively localized at the centromeres of 20 small chromosomes. The merged images clearly distinguished two groups of differentiated chromosomes, 10 larger ones of different size and 20 smaller ones of similar size. Comparison of the results of the sequential hybridization experiments showed that the faint pTa71 and the proximal
pTa794 signals were located on chromosomes belong to the group of 10 chromosomes, while the stronger signals observed with pTa71 and the distal pTa794 mapped to chromosomes of the 20 chromosome group (compare Figs. 3a and 3b).

The data matrix on the presence/absence of the 22 LMW-GS in each population was used to compute the output matrix of Dice's similarity coefficient for interval measure among populations of all cytotypic groups. The coefficients were used to produce a cluster using the unweighted pair-group method (UPGMA). The data derived from the analysis of similarity were used to construct dendrograms. The dendrogram of Fig. 4 is based on Dice's coefficient (other functions were also essayed, such as Jaccard, giving a similar dendrogram). The following should be noted: (a) there is considerable ramification, reflecting the great variation both within and between populations for the endosperm proteins; (b) two welldefined groups separating the $2 n=10$ forms from the $2 n=20$ plus $2 n=30$ forms can be clearly appreciated; (c) the branch that groups the populations with more than 10 chromosomes shows two clear subgroups separating the populations with $2 n=20$ (upper part of the dendrogram) and $2 n=30$ forms (middle of the dendrogram) (Fig. 5).

\section{Discussion}

The oldest classification of wheat seed proteins is based on their different dilution properties (Osborne 1924) and involves four main fractions: albumins (soluble in water), globulins (soluble in saline solutions), gliadins (soluble in diluted alcohol) and glutenins (soluble in acid solutions or alkalis). Even though the four types show clear biochemical differences, their solubility in different solvents is not absolutely discriminatory. The major protein groups of the endosperm of wheat are the glutenins and gliadins, which together are known as prolamins owing to their high content of proline and glutamine. They make up about $80 \%$ of the total protein of the grain, are synthesized in the endoplasmic reticulum in the final stages of maturation and are deposited as the main nitrogen reserve in the cytoplasm in the form of "protein bodies" for mobilization and use during germination (Shewry and Mifflin 1985).

A recent study on major seed storage proteins in a diploid accession of this species reports the main protein component to involve the $12 \mathrm{~S}$ and $7 \mathrm{~S}$ globulin types (Laudencia-Chingcuanco and Vensel 2008). A subset of the major seed proteins isolated from three hexaploid accessions was been also identified as globulins. Larré et al. (2010) recently studied the protein composition of caryopses of a $2 n=10$ accession of Brachypodium by separating the proteins on the basis of their solubility, 


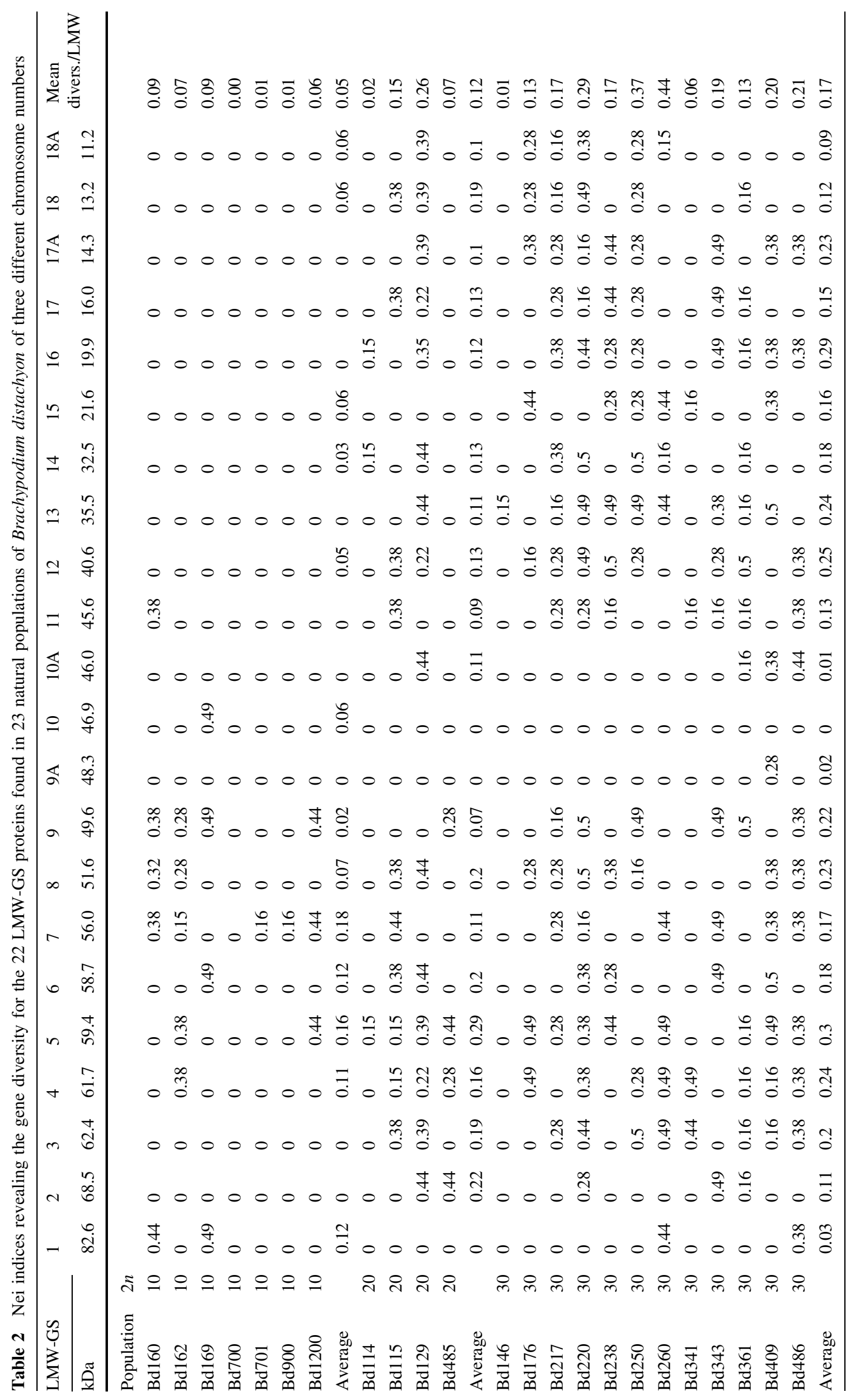




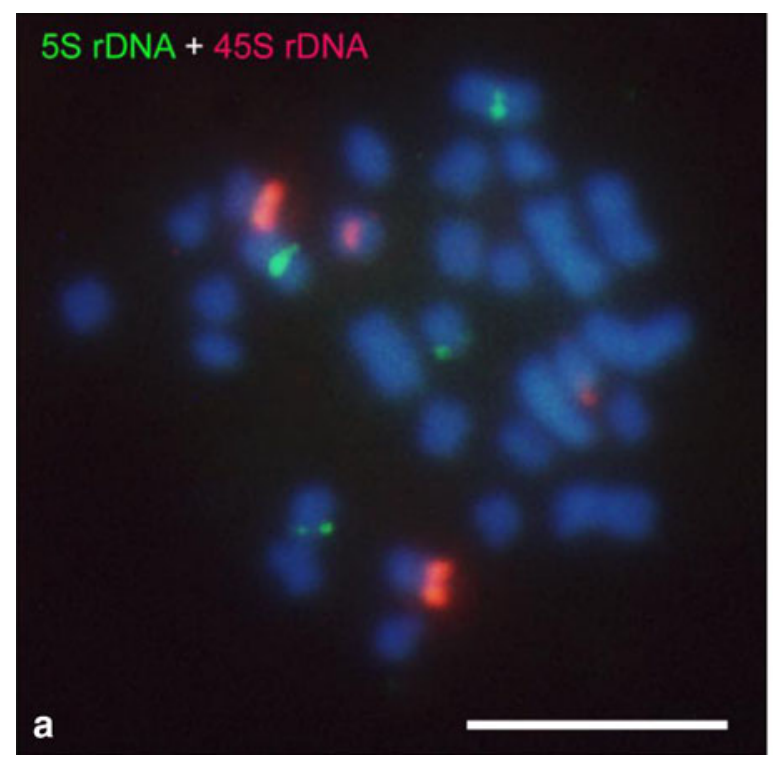

Fig. 3 Confirmation that the $2 n=30 B$. distachyon cytotype is of alloploid origin. a FISH of the rDNA probes pTa71 (four red signals) and 5S rDNA pTa794 (four green signals) to metaphase of Bd146

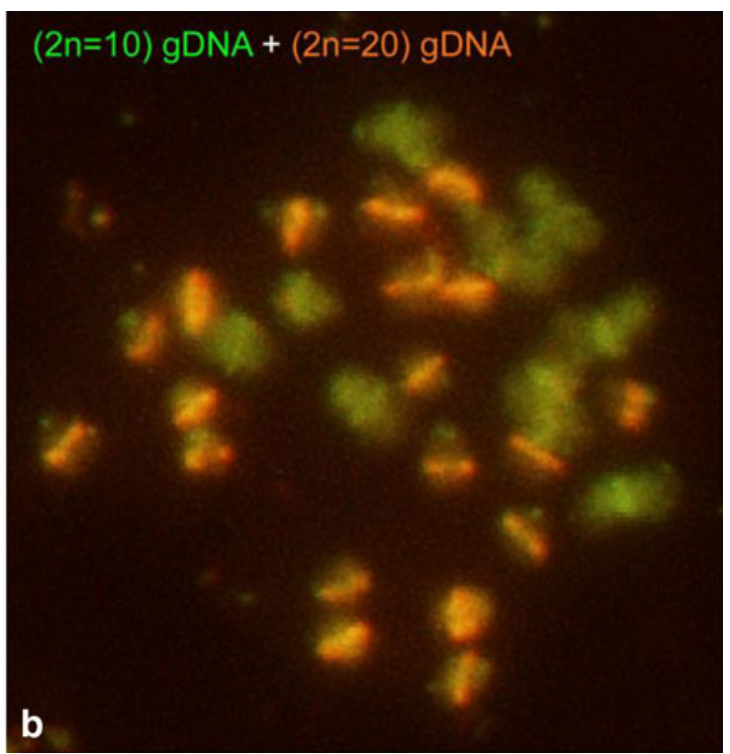

$(2 n=30)$. b The same metaphase after reprobing with genomic DNA from $\operatorname{Bd} 3113(2 n=10)$ (green $)$ and $\operatorname{Bd} 129(2 n=20)$ (red signals). Scale bar $=10 \mu \mathrm{m}$
Fig. 4 Dendrogram grouping 23 wild populations of B. distachyon inferred from the presence/absence of each glutenin subunits in 12 plants per population. The commercial lines 'Ibros' (3107) and

'Zulema' (3113) were included as controls

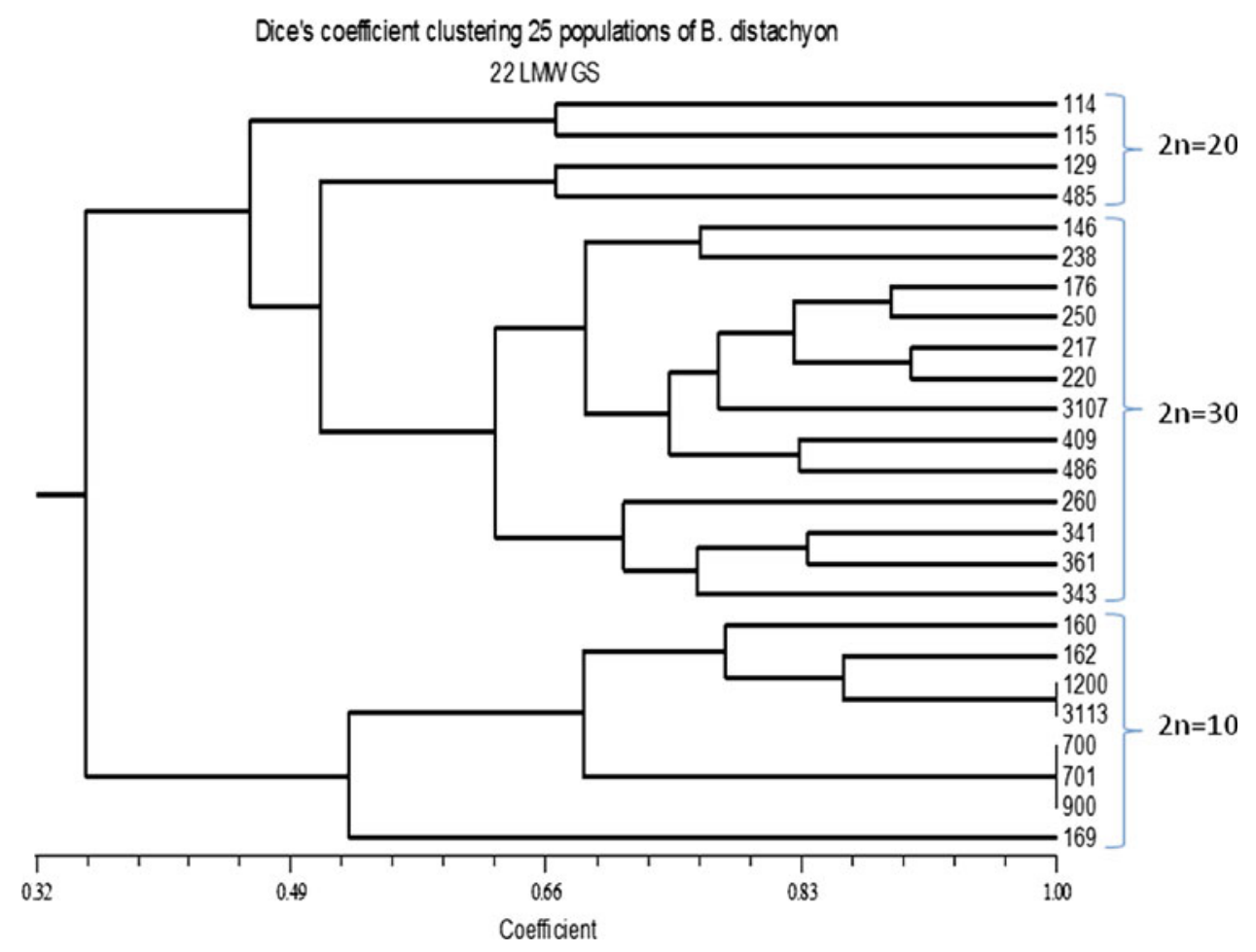

combining this with proteomic analyses. These authors detected globulins and prolamins, but no albumins. Globulins were represented mainly by the $11 \mathrm{~S}$ type, and their solubility properties corresponded to the glutelin found in rice. Wang et al. (2010) found abundant wheat LMWGS-like proteins and a few HMW-GS with low levels of expression in three $2 n=10$ and 10 accessions of B. distachyon with $2 n=30$ analyzed by SDS-PAGE and other techniques. In total, more than 20 different bands in the LMW-GS region and 15 albumin proteins were identified in these materials.

The present study followed a specific method to extract the glutelins, which were then separated by SDS-PAGE. The result was the identification of at least 22 distinguishable bands corresponding to the wheat LMW-GS-like proteins. These showed a high degree of variability within and between 
Fig. 5 Correspondence analysis displaying the distribution of 23 wild populations of $B$. distachyon. Six climatic and ecogeographical variables have been contemplated. The populations distribute themselves in two sub-groups that delimit the forms of $2 n=10$ from the others ( $2 n=20$ and $2 n=30)$. The forms with $2 n=20$ have been marked with asterisk

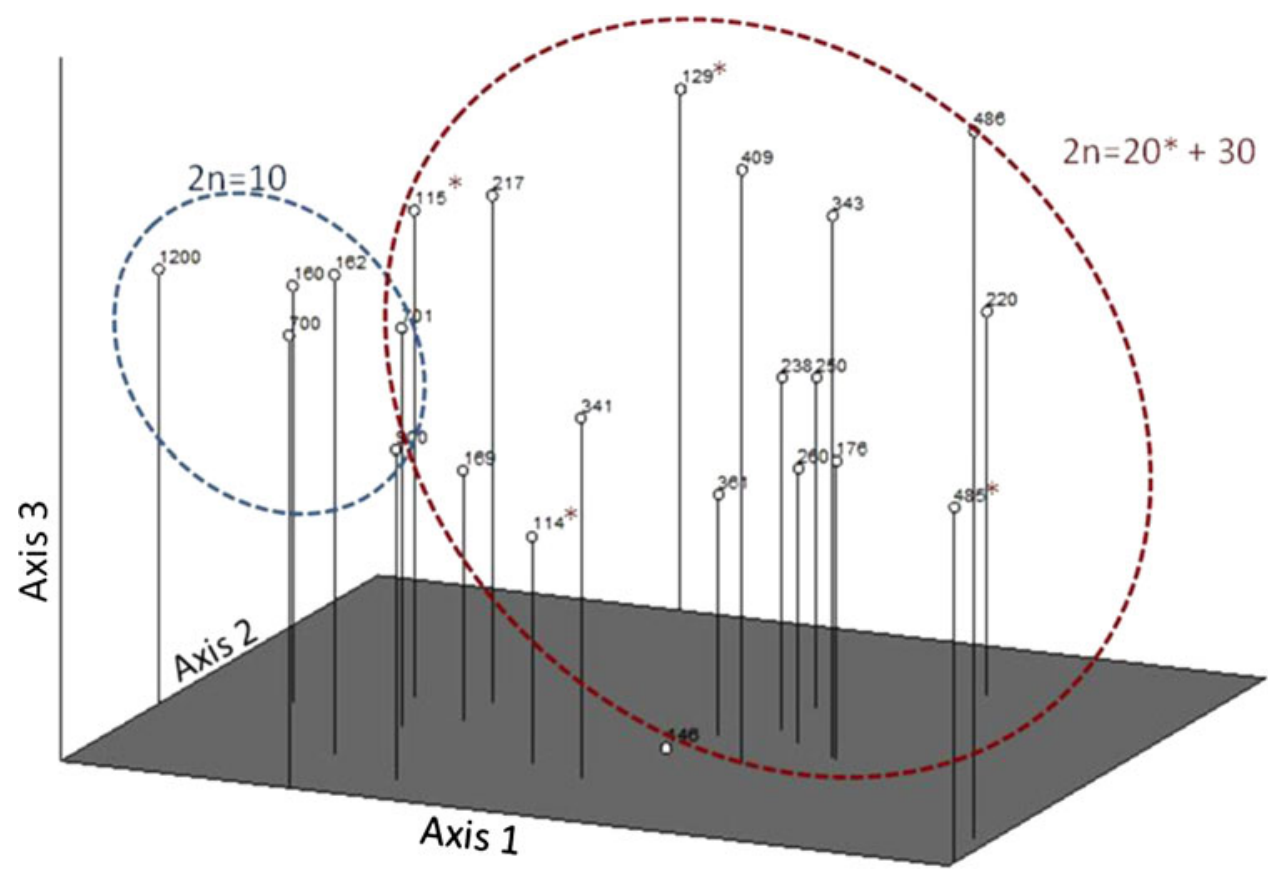

the $2 n=10,2 n=20$ and $2 n=30$ accessions investigated. These proteins must be considered wheat LMW-GS-like due to the method of extraction that released them and their correspondence with the proteins characterized by Wang et al. (2010).

Protein variability in the populations of $B$. distachyon has been poorly documented to date. The present work, however, reveals the great variation of endosperm proteins shown across the species. A population is considered polymorphic when there is variation in at least one band and/or pattern in at least one individual in a population (Asíns and Carbonell 1986; Soler et al. 1993). In agreement with this criterion, all the natural populations investigated can be classed as polymorphic for the endosperm proteins studied.

The $2 n=30$ forms showed the greatest diversity, followed by the $2 n=20$ and finally the $2 n=10$ forms. According to Nevo (1978), the variability found in autogamous species could be due to their location. Thus, those populations with wide distributions ought to be relatively more polymorphic and heterogeneous than those with more restricted distributions. The natural populations of an autogamous species tend to be constituted by homozygous genotypes. The LMW-GS-like proteins observed in the natural populations of $B$. distachyon indicate the existence of a mixture of plants within each population, although there was always a predominant pattern. The different patterns might represent distinct homozygous genotypes, which might be maintained from one generation to the next as pure lines by self-pollination. Certainly, the natural populations of $B$. distachyon showed more variation than expected with regard to their autogamous breeding system. In agreement with Stebbins (1975), it is to be expected that when an autogamous species extends towards new habitats that it should establish a greater number of different lines than would a population that for generations has remained in the same habitat. This might be the circumstances of the populations of $B$. distachyon in the Iberian Peninsula, near the limit of the species' distribution. It is also possible, however, that the difference in variability is the consequence of different degrees of allogamy influenced by environmental factors (Sanders and Hamrick 1980; Schoen and Clegg 1985; Golenberg 1988; Monte et al. 1999; Nieto et al. 2000, 2003).

Vogel et al. (2009) characterized the natural diversity in Turkish populations of B. distachyon using simple sequence repeat (SSR) markers and demonstrated that under growth chamber and greenhouse conditions the flowers of $2 n=10$ plants rarely open. Only under certain environmental conditions (warm and humid in full sun) were open flowers observed on $2 n=10$ plants growing outside greenhouse. The same authors monitored the rate of pollen flow using potential transgenic pollinators and demonstrated that the rate of outcrossing under laboratory conditions is exceedingly small. The same authors reported that 'polyploid' forms show exerted anthers, which could imply the existence of allogamy in these cases. This, and the possession of duplicated genomes, could explain why the $2 n=30$ plants present more diversity.

To analyze the influence of eco-geographic and climatic factors in the distribution of the studied populations, 
Table 3 Correlation between the gene diversity (Nei index) and the number of chromosomes and six eco-geographic and climatic variables for the $23 \mathrm{~B}$. distachyon populations studied

\begin{tabular}{llr}
\hline & Nei index & \multicolumn{1}{l}{$2 n$} \\
\hline $2 n$ & $-0.468^{*}$ & \\
Altitude & $-0.885^{* *}$ & $-0.558^{* * *}$ \\
Latitude & $-0.44^{*}$ & $-0.628^{* * *}$ \\
Annual mean temperature & -0.24 & $0.577^{* * *}$ \\
Thermicity index (It) & $-0.916^{* * *}$ & $0.569^{* * *}$ \\
Annual precipitation & -0.317 & $-0.547 * * *$ \\
Mediterraneity index (IM3) & -0.261 & $0.586^{* * *}$ \\
\hline
\end{tabular}

$* 0.05>P>0.01, * * 0.01>P>0.001, * * * P<0.001$

analysis of correspondence was performed using a two-way contingency matrix that included the number of chromosomes and the data of six geographic and climatic variables corresponding to the sites of natural populations. The results indicate the main factors that influence the three first axes of correspondence ( $96.58 \%$ of the total variance) to be altitude, latitude, summer precipitation, the index of Mediterraneity, the thermicity index and the annual mean temperature.

An analysis was then made of the possible correlation between the mentioned eco-geographic and climatic factors and the diversity shown by the endosperm proteins in the populations, represented by the Nei index (Table 3). The diversity correlated positively with the number of chromosomes $(2 n)$, annual mean temperature, index of thermicity and index of Mediterraneity. In contrast, diversity correlated negatively with altitude, latitude and index of summer precipitation. The number of chromosomes correlated negatively with altitude, latitude and summer precipitation and positively with all the other climatic indices. These results are coherent with the fact that diploid forms were more common in the populations collected from the interior and at higher altitude, where the climate is more extreme.

The present study highlights the habitat preferences and degree of heterogeneity shown by the forms of B. distachyon with different numbers of chromosomes as determined by DAPI staining, FISH and GISH. The two small pairs of chromosomes of the $2 n=10$ cytotype bear a $45 \mathrm{~S}$ locus in the distal region of the short arm and a major $5 \mathrm{~S}$ rDNA locus in the proximal region of the long arm. These sequences are located in the distal regions of two different pairs of chromosomes in the $2 n=20$ cytotype. The chromosomes of the $2 n=20$ form are considerably smaller than those of the $2 n=10$ form. The $2 n=30$ cytotype shows the same characteristics of chromosome size and positioning as the $45 \mathrm{~S}$ and $5 \mathrm{~S}$ rDNA sequences of both the $2 n=10$ and $2 n=20$ forms, suggesting it to be alloploid in origin as proposed by Hasterok et al. (2004).
These differences seem to corroborate the proposal made by Hasterok et al. (2004) that the forms of Brachypodium with different chromosome number be separated into different taxonomic units. This separation has also been suggested on the basis of $\mathrm{C}$-values and the different size of the sets of chromosomes observed by FISH. Hasterok et al. (2004) used FISH to analyze different accessions of Brachypodium and found the $2 n=20$ forms to have small chromosomes more similar to those of $B$. sylvaticum than to the larger chromosomes found in $2 n=10$ accessions of $B$. distachyon. Moreover, $2 n=30$ accessions are reported to have $\mathrm{C}$-values approximately twice as large as those for the $2 n=10$ forms (Vogel et al. 2006), and their karyotypes seem to represent the addition of the chromosomes of the $2 n=10$ and $2 n=20$ forms. All this suggests that the $2 n=30$ forms are allotetraploids formed by hybridization between $2 n=10$ and $2 n=20$ forms, followed by chromosome doubling (Hasterok et al. 2004). Moreover, all three cytotypes with $2 n=10,20$ and 30 chromosomes in this study belong to $B$. distachyon and have been collected in the Iberian Peninsula. Thus, the alloploid origin proposed by Hasterok et al. (2004) is possible also within $B$. distachyon with different cytotypes. The smaller number of endosperm protein subunits shared by the $2 n=10$ and $2 n=20$ forms than between either of the above and the $2 n=30$ forms corroborates the possible allopolyploidal origin of the $2 n=30$ forms. Some authors have already proposed the classification of the different ploidy forms of $B$. distachyon as a different species (Hasterok et al. 2004, 2006; Idziak and Hasterok 2008).

Acknowledgments This study was supported by grants from the Spanish Ministry of Science and Innovation (AGL 2009-10373). The authors thank Adrian Burton for linguistic assistance.

Open Access This article is distributed under the terms of the Creative Commons Attribution Noncommercial License which permits any noncommercial use, distribution, and reproduction in any medium, provided the original author(s) and source are credited.

\section{References}

Asíns MJ, Carbonell EA (1986) A comparative study on variability and phylogeny of Triticum species. 1. Intraspecific variability. Theor Appl Genet 72:551-558

Catalan P, Olmstead RG (2000) Phylogenetic reconstruction of the genus Brachypodium. Beauv. (Poaceae) from combined sequences of chloroplast gene and nuclear ITS. Plant Syst Evol 220:1-19

Catalan P, Kellogg EA, Olmstead RG (1997) Phylogeny of Poaceae subfamily Pooideae based on chloroplast $n d h F$ gene sequences. Mol Phylogen Evol 8:150-166

Cuadrado A, Acevedo R, Moreno Diaz De La Espina S, Jouve N, De La Torre C (2004) Genome remodelling in three modern $S$. officinarum $\times S$. spontaneum sugarcane cultivars. J Exp Bot $55: 847-854$ 
Doust A (2007) Architectural evolution and its implications for domestication in grasses. Ann Bot 100:941-950

Draper J, Mur LAJ, Jenkins G, Ghosh-Biswas GC, Bablak P, Hasterok R, Routledge APM (2001) Brachypodium distachyon a new model system for functional genomics in grasses. Plant Physiol 127:1539-1555

Filiz E, Ozdemir BS, Budak F, Vogel JP, Tuna M, Budak H (2009) Molecular, morphological, and cytological analysis of diverse Brachypodium distachyon inbred lines. Genome 52(10):876-890

Garvin DF (2007) Brachypodium: a new monocot model plant system emerges. J Sci Food Agric 87:1177-1179

Garvin DF, Gu Y, Hasterok R, Hazen S, Jenkins G, Mockler T, Mur LJ, Vogel JP (2008) Development of genetic and genomic research resources for Brachypodium distachyon, a new model for grass crop research. Crop Sci 48:S69-S84

Gerlach WL, Bedbrook JR (1979) Cloning and characterization of ribosomal RNA genes from wheat and barley. Nucleic Acids Res 7:1869-1885

Gerlach WL, Dyer TA (1980) Sequence organization of the repeating units in the nucleus of wheat that contain 5S rDNA genes. Nucleic Acids Res 8:4851-4865

Golenberg EM (1988) Outcrossing rates and their relationship to phenology in Triticum dicoccoides. Theor Appl Genet 75:937-944

Hasterok R, Draper J, Jenkins G (2004) Laying the cytotaxonomic foundations of a new model grass Brachypodium distachyon (L.) Beauv. Chromosom Res 12:397-403

Hasterok R, Marasek A, Donnison IS, Armsted I, Thomas A, King IP, Wolny E, Idziak D, Draper J, Jenkins G (2006) Alignement of the genomes of Brachypodium distachyon and temperate cereals and grasses using bacterial artificial chromosome landing with fluorescence in situ hybridisation. Genetics 173:349-362

Hawkes JG (1980) Crop genetic resources. Field collection manual for seed crops, roots and tuber crops, tree fruit crops and related wild species. IBPGR/EUCARPIA, Rome

Higgins JA, Bailey PC, Laurie DA (2010) Comparative genomics of flowering time pathways using Brachypodium distachyon as a model for the temperate grasses. PLoS ONE 5(4):e10065. doi: 10.1371/journal.pone.0010065

Huo N, Lazo G, Vogel J, You F, Ma Y, Hayden DM, Coleman-Derr D, Hill T, Dvorak J, Anderson OD, Luo M, Gu YQ (2008) The nuclear genome of Brachypodium distachyon: analysis of BAC and sequences. Funct Integr Genomics 8:135-147

Huo N, Vogel JP, Lazo GR, You FM, Ma Y, McMahon S, Dvorak J, Anderson OD, Luo MC, Gu YQ (2009) Structural characterization of Brachypodium genome and its syntenic relationship with rice and wheat. Plant Mol Biol 70:47-61

Idziak D, Hasterok R (2008) Cytogenetic evidence of nucleolar dominance in allotetraploid species of Brachypodium. Genome $51: 387-391$

Kellogg EA (2001) Evolutionary history of the grasses. Plant Physiol 125:1198-1205

Larré C, Penninck S, Bouchet B, Lollier V, Tranquet O, DeneryPapini S, Guillon F, Rogniaux H (2010) Brachypodium distachyon grain: identification and subcellular localization of storage proteins. J Exp Bot 61(6):1771-1783. doi:10.1093/jxb/erq050

Laudencia-Chingcuanco DL, Vensel WH (2008) Globulins are the main seed storage proteins in Brachypodium distachyon. Theor App Genet 117:555-563

Monte JV, Casanova C, Soler C (1999) Genetic variation in Spanish populations of the genus Aegilops revealed by RAPDs. Agronomie 9:419-427

Nevo E (1978) Genetic variation in natural populations: pattern and theory. Theor Populat Biol 13:121-177

Nieto RM, Casanova C, Soler C (2000) Analysis of the genetic diversity of wild Spanish populations of the species Elymus caninus (L.) Linnaeus and Elymus hispanicus (Poiss) Talavera by PCR-based markers and endosperm. Agronomie 21:893-905

Nieto RM, Soler C, García P (2003) Genetic diversity in wild Spanish populations of Thinopyrum junceum and Thinopyrum junceiforme using endosperm proteins and PCR-based markers. Hereditas 139:18-27

Opanowicz M, Vain P, Draper J, Parker D, Doonan JH (2008) Brachypodium distachyon: making hay with a wild grass. Trends Plant Sci 13:172-177

Osborne TB (1924) The vegetable proteins, 2nd ed edn. Longmans Green, London

Ozdemir BS, Hernandez P, Filiz E, Budak H (2008) Brachypodium genomics. Int J Plant Genomics 536104. doi:10.1155/2008/ 536104

Rivas-Martínez S, Lousa M, Díaz TE, Costa J (1990) La vegetación del Sur de Portugal (Sado, Alentejo y Algarve). Itin Geobot 3:5-126

Robertson IH (1981) Chromosome numbers in Brachypodium (Poaceae). Plant Syst Evol 188:125-138

Rolf JF (1994) NTSYS-pc. Numerical taxonomy and multivariate analysis system. Pc versión. 2.11. Exeter Software Applied Biostatistics Inc, New York

Sanders TB, Hamrick JL (1980) Variation in the breeding system of Elymus Canadensis. Evolution 34:117-122

Schoen DJ, Clegg MT (1985) The influence of flower colour on outcrossing rate and male reproductive success in Ipomoea purpurea. Evolution 39:1242-1249

Shewry PR, Mifflin BJ (1985) Seed storage proteins of economically important cereals. Adv Cereal Sci Technol 7:1

Shewry PR, Tathan AS (1995) Seed storage proteins: structure and biosynthesis. Plant Cell 7:945-956

Shi Y, Draper J, Stace C (1993) Ribosomal DNA variation and its phylogenetic implication in the genus Brachypodium (Poaceae). Plant Syst Evol 188:125-138

Singh NK, Shepherd KW, Cornish GB (1991) A simplified SDSPAGE procedure for separating LMW subunits of glutenin. J Cereal Sci 14:203-208

Sneath PHA, Sokal RR (1973) Numerical taxonomy. Freeman, San Francisco

Soler C, Galindo C, Garcia P, Gonzalez-Castaño S, Casanova C (1993) Isozyme variation in Spanish natural populations of Elytrigia pungens (pers.) and Elytrigia repens (L.) Newski. Heredity 71:51-58

Soler C, Casanova C, Rojo A (2004) Desarrollo de cubiertas vegetales a partir de gramíneas seleccionadas, para su explotación en tierras de olivar. Actas Hortic 41:97-100

Sorensen $T$ (1948) A method of establishing groups of equal amplitude in plant sociology based on similarity of species content and its application to analyses of the vegetation on Danish commons K. Dan. Vidensk. Selsk. Biol Shar 5:1-34

Stebbins GL (1975) The role of polyploid complexes in the evolution of North American grasslands. Taxon 24:91-106

Thornthwaite CW (1948) An approach toward a rational classification of climate. Geograph Rev 38(1):55-94

Vain P, Worland B, Thole V, Mckenzie N, Alves SC, Opanowicz M, Fish L, Bevan M, Snape JW (2008) Agrobacterium-mediated transformation of the temperate grass Brachypodium distachyon (genotype Bd 21) for T-DNA insertional mutagenesis. Plant Biotech J 6:236-245

Vogel J, Hill T (2008) High-efficiency Agrobacterium-mediated transformation of Brachypodium distachyon inbred line $\mathrm{Bd} 21-3$. Plant Cell Rep 27:471-478

Vogel JP, Gu YQ, Twigg P, Lazo GR, Laudencia-Chingcuanco D, Hayden DM, Donze TJ, Vivian LA, Stamova B, Coleman-Derr D (2006) EST sequencing and phylogenetic analysis of the 
model grass Brachypodium distachyon. Theor Appl Genet 113(2):186-195

Vogel JP, Tuna 1M, Budak H, Huo N, Gu YQ, Steinwand MA (2009)

Development of SSR markers and analysis of diversity in Turkish populations of Brachypodium distachyon. BMC Plant Biol 9:88. doi:10.1186/1471-2229-9-88
Wang K, Han X, Dong K, Gao L, Li H, Ma W, Yan Y (2010) Characterization of seed proteome in Brachypodium distachyon. J Cereal Sci 52, doi:10.1016/j.jcs.2010.05.001 